\title{
QUALIDADE E PRODUTIVIDADE DE FRUTOS DE FIGO CULTIVADO EM TRÊS DENSIDADES DE PLANTIO
}

\author{
Scheila Lucia Ecker ${ }^{1}$, Clevison Luiz Giacobbo ${ }^{2}$, Leandro Galon ${ }^{1}$, Adriana Lugaresi ${ }^{2}$, Gian Carlos Girardi ${ }^{2}$ \\ ${ }^{1}$ Universidade Federal da Fronteira do Sul - UFFS, Agronomia, Campus Erechim, RS. ${ }^{2}$ Universidade Federal da Fronteira \\ do Sul - UFFS, Agronomia/PPGCTA, Campus Chapecó, SC. E-mail: clevison.giacobbo@uffs.edu.br
}

\begin{abstract}
RESUMO
Objetivou-se com este trabalho verificar a influência da densidade de plantio na produtividade e qualidade dos frutos da figueira. O delineamento utilizado foi em três blocos, com os tratamentos distribuídos ao acaso, onde as plantas foram da cultivar Roxo de Valinhos foram submetidas a três densidades de plantio: 5 x 0,5 m; 5 × 1,0 m; e $5 \times 1,5 \mathrm{~m}$. Cada repetição foi composta por cinco plantas. As características avaliadas foram: comprimento de ramos; crescimento médio semanal de ramos; tamanho de fruto; peso médio de fruto; sólidos solúveis ( ${ }^{\circ}$ Brix); produtividade de frutos maduros; produtividade de frutos verdes; produtividade acumulada; e massa seca dos frutos. O comprimento dos ramos não foi influenciado pelo espaçamento de plantio, as plantas conduzidas em menores densidades apresentaram produtividade superior, tanto de frutos verdes como produtividade acumulada. Plantas submetidas a menor densidade de plantio produziram frutos de maior matéria seca, porém estes eram de menor tamanho, mas sem diferença significativa para aquelas submetidas a menor densidade. Conclui-se que a produtividade é diretamente afetada pela densidade de plantio de figueira, mas nem todos os aspectos qualitativos dos frutos foram afetados.
\end{abstract}

Palavras-chave: Ficus carica L., espaçamentos de plantio; Roxo de Valinhos.

\section{QUALITY AND PRODUCTIVITY OF FIG FRUITS CULTIVATED IN THREE PLANT DENSITIES}

\begin{abstract}
The objective of this work was to verify the influence of planting density on productivity and fruit quality of the fig tree. The design was used in three blocks, the plants of the cultivar Roxo de Valinhos were submitted to three planting spacings: $5 \times 0.5 \mathrm{~m} ; 5 \times 1.0 \mathrm{~m}$; and $5 \times 1.5 \mathrm{~m}$. The evaluated characteristics were: length of branches; average weekly growth of branches; fruit size; average fruit weight; soluble solids ( ${ }^{\circ} \mathrm{Brix}$ ); yield of mature fruits; productivity of green fruits; accumulated productivity; and dry mass of fruits. The length of the branches was not influenced by planting spacing, the plants conducted at lower densities presented higher productivity, both of green fruits and accumulated productivity. Plants submitted to lower planting density produced fruits with higher dry matter, but these were smaller in size, but without significant difference for those submitted to lower density. It was concluded that productivity is directly affected by fig planting density, but not all the qualitative aspects of the fruits were affected.
\end{abstract}

Keywords: Ficus carica L; plant spacing; Roxo of Valinhos.

\section{INTRODUÇÃO}

A cultura da figueira (Ficus carica L.) quando comparada as outras espécies frutíferas apresenta baixo custo de implantação e precocidade de produção, sendo que esta iniciase no primeiro ano após o plantio, e devido a isso, tem sido uma cultura pioneira nos programas de incentivo a fruticultura. Apresenta estabilidade produtiva a partir do terceiro ano de produção, quando as plantas já estão formadas pela poda de condução (CAETANO et al., 2005).

$\mathrm{Na}$ implantação de um pomar a escolha da densidade de plantio é um dos principais fatores para o sucesso da produção. A alta densidade pode apresentar vantagens em relação à baixa densidade, reduzindo o período improdutivo do pomar, possibilitando maior produção inicial por área, maior eficiência da 
terra, maior eficiência de colheita pela padronização na maturação. No entanto, os custos de implantação se tornam mais elevados, além da dificuldade de manutenção da eficiência produtiva e menor duração do período econômico do pomar (RASEIRA et al., 2007).

Apesar de a figueira ser uma cultura que se adapta a diversas condições edafoclimáticas, o seu cultivo ainda é feito de forma tradicional, sem muitas melhorias técnicas e inovações tecnológicas (GIACOBBO et al., 2007). Como forma de buscar melhoria técnica do cultivo, este trabalho buscou dar um primeiro passo, o qual inicia-se pela implantação, através da avaliação de espaçamentos e suas consequências em termos produtivos e de qualidade de frutos, para que os produtores tenham acesso a essa informação tão imprescindível no momento da implantação de novos pomares, e esse é o diferencial deste trabalho.

Diante disso, objetivou-se com este trabalho verificar a influência da densidade de plantio na produtividade e qualidade dos frutos de figos para a cultivar Roxo de Valinhos.

\section{MATERIAL E MÉTODOS}

O experimento foi conduzido em um pomar de figueira cultivar Roxo de Valinhos, em Chapecó, Santa Catarina, localizado a Latitude de $27^{\circ} 07^{\prime} 11$ 'S, Longitude $52^{\circ} 42^{\prime} 30^{\prime \prime} \mathrm{E}$ e altitude de $610 \mathrm{~m}$. O clima, segundo a classificação de Köppen é categoria C, subtipo Cfa (Clima subtropical húmido) e o solo, segundo Embrapa (2004) é classificado como Latossolo Vermelho Distroférrico. O pomar foi implantado no ano de 2014, em diferentes espaçamentos de plantio e em 2015 foi realizado o experimento.

O delineamento utilizado foi em blocos com os tratamentos distribuidos ao acaso, com três repetições, sendo os tratamentos as densidades de plantio: $5 \times 0,5 \mathrm{~m} ; 5 \times 1,0 \mathrm{~m}$; e $5 \times$ $1,5 \mathrm{~m}$; e cada repetição composta por cinco plantas

Realizou-se a poda de inverno ou poda de produção em 22 de agosto de 2015 . A colheita de frutos maduros teve início em 20 de janeiro de 2016. Durante o período foram realizadas roçadas para controle de plantas daninhas, a cobertura de solo constituida por aveia-preta de inverno, foi acamada na entre-linha no estágio de grão leitoso e roçada na linha de plantio e mantida como cobertura, auxiliando no controle. Sendo aplicado uma aplicação de calda bordaleza para controle de doenças.

As carcterísticas analisadas foram: crescimento médio semanal de ramos e comprimento final de ramos: considerando-se a base do ramo até a ponta da gema apical; tamanho de fruto: mensurados com auxílio de paquímetro (mensurado no sentido transversal e longitudinal); peso médio de fruto; sólidos solúveis ( $\left.{ }^{\circ} \mathrm{BRIX}\right)$ determinado por leitura em refratômetro digital; produtividade de frutos maduros; produtividade de frutos verdes; produtividade acumulada: obtida através da somatória entre frutos maduros e frutos verdes, e matéria seca dos frutos: determinada através de secagem em estufa com ventilação de ar forçado, aquecida a $65^{\circ} \mathrm{C} \pm 2$.

Os dados obtidos foram testados quanto à normalidade e homogeneidade e posteriormente submetidos à análise de variância pelo teste $\mathrm{F} \mathrm{e}$, quando significativos, submetidos à comparação por meio do teste de Duncan a $5 \%$ de probabilidade. Os dados foram analisados utilizando o programa estatístico WinStat (MACHADO; CONCEIÇÃO, 2005).

\section{RESULTADOS E DISCUSSÃO}

Observa-se na Figura 1 que 0 comprimento de ramos avaliados a cada sete dias apresentou crescimento linear em função dos dias estudados, apresentando aos 126 dias (última avaliação), ramos com média de $140 \mathrm{~cm}$. Verifica-se, portanto que, os ramos de figueira após a última avaliação, realizada em metade de abril, ainda tem potencial de crescimento, no entanto, a tendência é que esse crescimento estabilize com a chegada do outono, período que as temperaturas já haviam começado a diminuir, visto que a temperatura mínima de abril foi $18,3^{\circ} \mathrm{C}$, além disso durante o período de avaliação, o mês de abril teve a menor precipitação $(75,4 \mathrm{~mm})$. 
Figura 1. Comprimento médio semanal de ramos de figueira cultivar Roxo de Valinhos, em função dos dias avaliados nos diferentes espaçamentos. As equações, seguem a ordem da legenda $(0,5 \mathrm{~m}, 1,0 \mathrm{~m}$ e $1,5 \mathrm{~m})$, respectivamente. Chapecó, 2018.

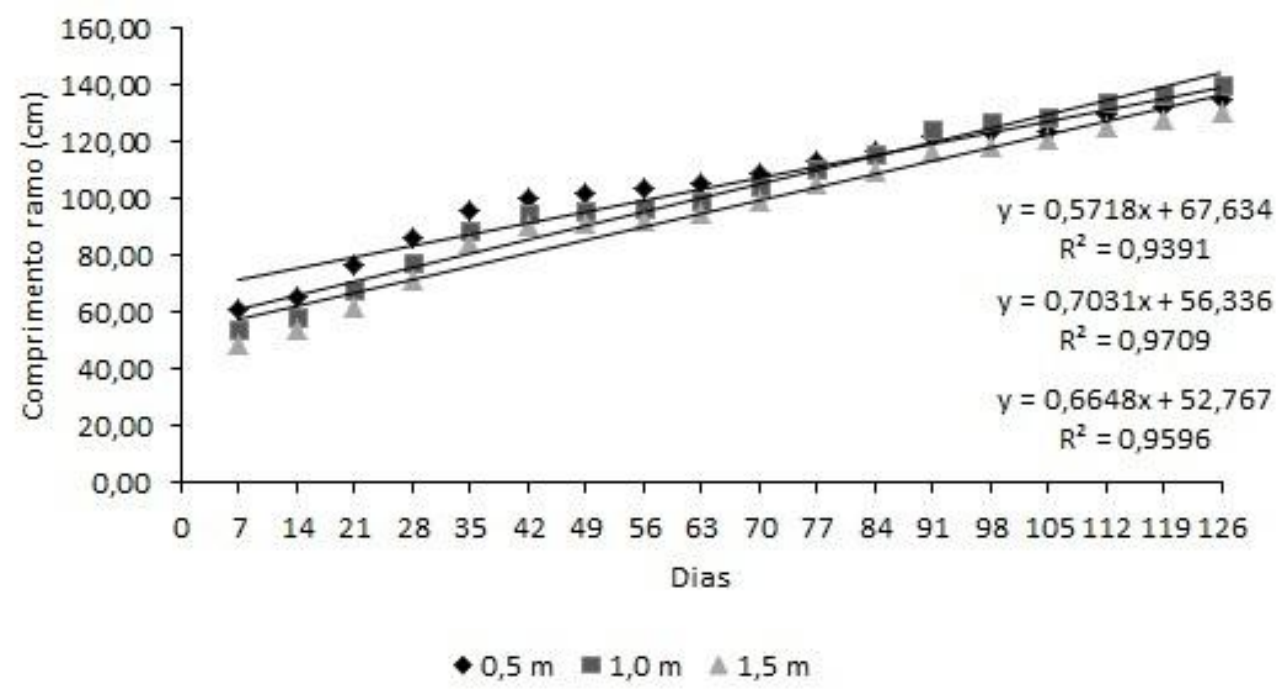

O comprimento médio final de ramos não apresentou diferença para as diferentes densidades de plantio, a média do comprimento final das plantas foi de $1,38 \mathrm{~m}$. Estudando plantas de pereira em diferentes densidades de plantio, Policarpo et al. (2006), observaram que as plantas submetidas ao plantio mais adensado tendem ao crescimento maior em altura, e aquelas cultivadas em sistema convencional alcançam maior volume de copa, possivelmente devido ao sombreamento e competição por luz, água e nutrientes.

Os dados observados neste trabalho diferem de Giacobbo et al. (2007) no qual o comprimento médio de ramos de figueira, apresentaram diferenças significativas entre os espaçamentos de plantio, sendo que aquelas conduzidas em $1,0 \mathrm{~m}$ apresentaram menor comprimento de ramo, comparando com 0,5 e $1,5 \mathrm{~m}$ que demonstraram superioridade.

A média de crescimento semanal de ramos não foi influenciado pela densidade de plantio, não apresentando diferença entre os tratamentos avaliados. A média de crescimento semanal foi de $4,56 \mathrm{~cm}$.

Kumar et al. (2014) avaliando o espaçamento de plantio e poda em figueira, observaram que plantas cultivadas em maiores densidades apresentaram maior crescimento de ramos, o que pode ser explicado pela necessidade de luz das plantas, que acabam crescendo mais em altura em busca de luz para realizar da fotossíntese. Villalobos et al. (2015) estudando crescimento fenológico de figueira em diferentes adensamentos de plantio também observaram maior comprimento de ramos para as plantas submetidas a maiores densidades.

A produtividade de frutos verdes e acumulada apresentou superioridade para o espaçamento de plantio $1,0 \mathrm{~m}$ e $1,5 \mathrm{~m}$ entre plantas, não havendo diferença entre si. Sendo que as plantas cultivadas em adensamento de 0,5 $\mathrm{m}$ entre plantas apresentaram os menores índices de produtividade, porém sem diferença significativa para aquelas submetidas a espaçamento de $1 \mathrm{~m}$ (Figura 2). Na produtividade de frutos maduros não encontrou-se diferença significativa, média de $278,2 \mathrm{~kg} \cdot \mathrm{ha}^{-1}$. A menor produtividade de frutos maduros, se deve pela ocorrência tardia de geada, 21 de setembro, forçando o rebrote das plantas tardiamente. 
Figura 2 -Produtividade de frutos verdes $\left(\mathrm{kg} \cdot \mathrm{ha}^{-1}\right)$, e produtividade acumulada $\left(\mathrm{kg} \cdot \mathrm{ha} \mathrm{a}^{-1}\right)$, para os espaçamentos de plantio: 0,5m, 1,0 m e 1,5m. Chapecó, 2018.

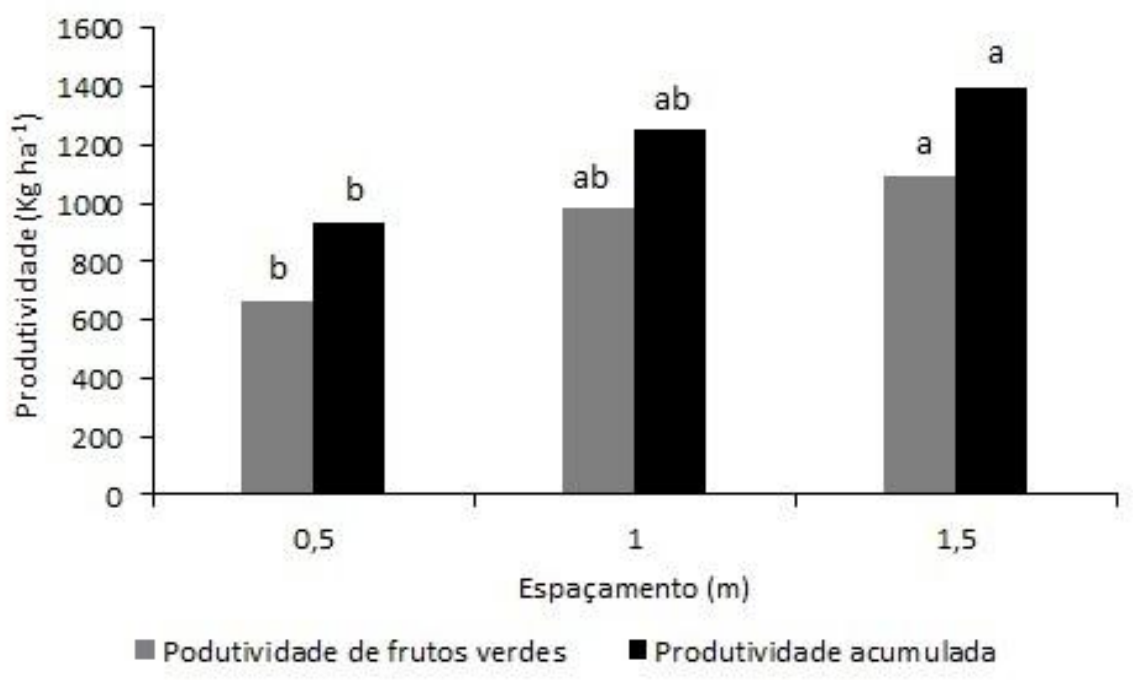

Médias seguidas de mesma letra, na mesma variável, não diferem estatisticamente entre si, pelo teste de Duncan a 5\% de probabilidade. CV: $17,99 \%$ e $15,54 \%$, respectivamente.

Os resultados obtidos podem ser em razão do maior sombreamento nas plantas conduzidas sob maior densidade. Sendo que as folhas sombreadas apresentam menor taxa fotossintética e consequentemente contribuem para a redução da produtividade das plantas (CAETANO et al., 2005).

As gemas frutíferas das figueiras estão localizadas nos nós dos ramos (PEREIRA; NACHTIGAL, 1999). Quanto maior for a intensidade da luz que chega no interior do dossel maior será o estímulo de formação de gemas frutíferas, pois o crescimento da planta e dos frutos bem como o desenvolvimento de gemas frutíferas necessitam dos carboidratos produzidos pela fotossíntese nas folhas (CAETANO et al., 2005).

Um manejo ideal no sistema de condução das plantas em conjunto com a densidade de plantio visa otimizar a produção de frutos, além de alterações nas relações fonte-dreno. Quando se reduz a área foliar com a poda, pode-se compensar com o aumento da densidade de plantio promovendo interceptação de luz solar suficiente para $\mathrm{o}$ bom desenvolvimento das plantas (DAVI, 2010).

Mayer et al. (2016) avaliando a produtividade de pêssegos da cultivar Chimarrita observaram que esta não foi influenciada pelas diferentes densidades de plantio testados no primeiro ano de avaliação.

As características peso médio de fruto, sólidos solúveis não foram influenciadas pela densidade de plantio, com média de 55,4g e 12,8 ${ }^{\circ}$ Brix, respectivamente. Ao analisar o tamanho de fruto (Figura 3) verificou-se que as plantas conduzidas em adensamento de 0,5 m entre plantas apresentaram frutos maiores em relação aqueles produzidos em plantas com densidade de $1,0 \mathrm{~m}$, não diferindo estatisticamente daqueles produzidos em espaçamento $1,5 \mathrm{~m}$. Para a análise de matéria seca, frutos oriundos de plantas com espaçamento de $1,5 \mathrm{~m}$ apresentaram maior porcentagem de massa seca. 
Figura 3. Efeito dos diferentes espaçamentos de plantio de figueira cultivar 'Roxo de Valinhos' sobre Tamanho de fruto (TF) e matéria seca (MS). Chapecó, 2018.
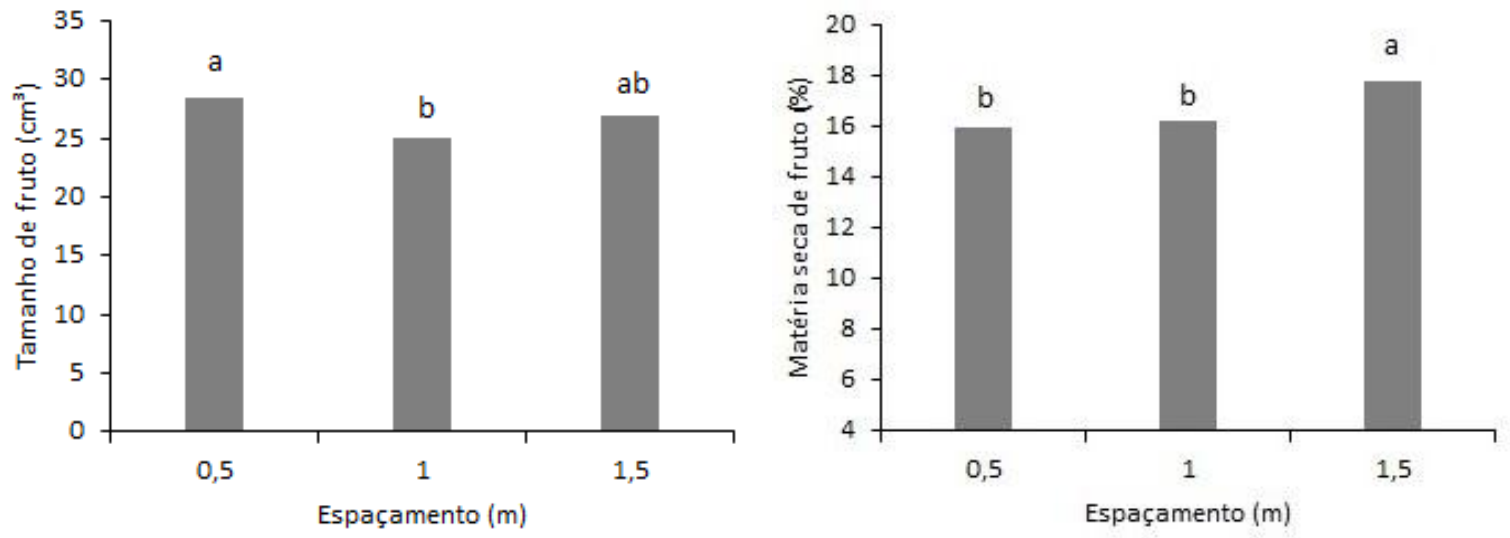

Médias seguidas de letra distinta na mesma variável, não diferem estatisticamente entre si pelo teste de Duncan, ao nível de 5\% de significância. CV: 5,38 e 1,51, respectivamente.

Em conformidade com os resultados obtidos neste trabalho Weber et al. (2016) avaliando frutos de maracujá, não observaram diferença estatística para sólidos solúveis nas diferentes densidades de plantio em maracujazeiro-azedo. Os mesmos autores também não observaram diferença estatística para a variável peso médio de fruto em função da densidade de plantio.

Resende e Costa (2003) avaliando a produtividade de melão para diferentes densidades de plantio observaram que os frutos do meloeiro apresentaram maior espessura de polpa em menores densidades, porém para sólidos solúveis não foi observado diferença estatística para os diferentes espaçamentos.

Portela et al. (2012) avaliando densidade de plantio e qualidade de frutos de morangueiro verificaram que os frutos não apresentaram diferenças significativas entre as densidades de plantio para a variável matéria seca total, resultado diferente ao encontrado neste presente trabalho.

\section{CONCLUSÃO}

A produtividade sofreu grande influencia da densidade de plantio na cultura da figueira, principalmente pelo fato de menores densidades contribuírem positivamente para o aumento da mesma.

A qualidade dos frutos sofreu pouca influência da densidade de plantio, apenas algumas características foram influenciadas.

Com base nestes aspectos, estes resultados contribuem para um primeiro passo na instalação de novos pomares de figueira, que vai depender do objetivo final do produtor.

\section{REFERÊNCIAS}

CAETANO, L. C. S.; CARVALHO, A. J. C.; CAMPOSTRINE, E.; SOUZA, E. F.; MURAKAMI, K. R. N.; CEREJA, B. S. Efeito do número de ramos produtivos sobre o desenvolvimento da área foliar e produtividade da figueira. Revista Brasileira de Fruticultura, v. 27, n. 3, p. 426-429, $2005 . \quad$ http://dx.doi.org/10.1590/S0100$\underline{29452005000300021}$

DAVI, J. J. S. Influência do espaçamento e da poda apical no tomateiro cultivado no sistema orgânico, em ambiente protegido. 2010. 110f. Dissertação (Mestrado em Agronomia) Universidade Estadual do Oeste do Paraná, Marechal Cândido Rondon.

EMBRAPA. Solos do Estado de Santa Catarina. Rio de Janeiro: Embrapa Solos, 2004. 745p. (Boletim de Pesquisa e Desenvolvimento 46).

GIACOBBO, C. L.; PICOLOTTO, L.; KRUGER, L. R.; PARISOTTO, E.; TIBOLA, C.; FACHINELLO, J. C. Cultivo da figueira conduzida em quatro diferentes densidades de plantio. Revista Brasileira de Agrociência, v. 13, p. 43-46, 2007. HTTP://DX.DOI.ORG/10.18539/CAST.V13I1.1309

KUMAR, R.; GANESH, S.; CHITHIRAICHELVAN, R.; UPRETI, K. K.; SULLADMATH, V. V. Effect of spacing and pruning on growth, yield and quality of cv. Deanna fig (Ficus carica L.). Journal of Horticultural Science, v. 9, n. 1, p. 31-37, 2014.

MACHADO, A.A.; CONCEIÇÃO, A.R. WinStat sistema de análise estatística para Windows. 
Versão Beta. Pelotas: Universidade Federal de Pelotas, 2005. (Software).

MAYER, N. A.; NEVES, T. R.; ROCHA, C. T.; LUCAS DA SILVA, V. A. Adensamento de plantio em pessegueiros 'Chimarrita'. Revista de Ciências Agroveterinárias, v. 15, n. 1, p. 50-59, 2016. DOI: $10.5965 / 223811711512016050$

PEREIRA, F.M.; NACHTIGAL, J.C. Botânica, biologia e cultivares de figueira. In: CORRÊA, L. DE S.; BOLIANI, A.C. Cultura da figueira: do plantio à comercialização. Ilha Solteira: FUNEP, 1999. p.2535.

POLICARPO, M.; TALLUTO, G.; LO BIANCO, R. Vegetative and productive responses of 'Conference' and 'Williams' pear trees planted at different in-row spacings. Scientia Horticulturae, v. $109, \quad$ p. $322-331,2006$. https://doi.org/10.1016/i.scienta.2006.06.009

PORTELA, I. P; PEIL, R. M. N.; RODRIGUES, S.; CARINI, F. Densidade de plantio, crescimento, produtividade e qualidade das frutas de morangueiro "Camino Real" em hidroponia. Revista Brasileira de Fruticultura, v. 34, n. 3, p. 792-798, 2012. http://dx.doi.org/10.1590/S0100$\underline{29452012000300019}$

RASEIRA, A.; RASEIRA, M.; ANTUNES, L. E.; PEREIRA, J. F. Influência da densidade de plantio na produtividade de cultivares de amoreira-preta. Revista Brasileira de Agrociência, v. 13, p. 551554, 2007. HTTP://DX.DOI.ORG/10.18539/CAST.V13I4.1400

RESENDE, G. M.; COSTA, N. D. Produção e qualidade do melão em diferentes densidades de plantio. Horticultura Brasileira, v. 21, n. 4, p. 690694, 2003. http://dx.doi.org/10.1590/50102$\underline{05362003000400024}$

VILLALOBOS, J. A. N.; RODRÍGUEZ, M. P.; RODRÍGUEZ, H. M.; GONZÁLEZ, M. R.; ARRIAGA, G. E. Dinámica de crecimiento fenológico de higuera (Ficus carica L.) com altas densidades de plantación em macro-tuneles. Agrofaz, v. 15, n. 2, p. 133-141, 2015.

WEBER, D.; ELOY, J.; GIOVANAZ, M. A.; FACHINELLO, J. C.; NACHTIGAL, J. C. Densidade de plantio e produção do maracujazeiro-azedo no sul do Brasil. Revista Brasileira de Fruticultura, v.
38, n. $1, \quad$ p. $99-106,2016$. http://dx.doi.org/10.1590/0100-2945-283/14

Recebido para publicação em 20/04/2018

Revisado em 03/07/2018

Aceito em 24/08/2018 